\title{
Invasive bacteria isolates from children with severe infections in a Nigerian hospital
}

\author{
Anthony O. Onipede ${ }^{1}$, Adedeji A Onayade ${ }^{2}$, Jerome B. E. Elusiyan ${ }^{3}$, Perpetua O Obiajunwa ${ }^{3}$, \\ Ezra O. O. Ogundare ${ }^{3}$, Olarinde O. Olaniran ${ }^{1}$, Lateef A. Adeyemi ${ }^{1}$, Oyeku O. Oyelami ${ }^{3}$
}

Departments of Medical Microbiology \& Parasitology ${ }^{1}$, Community Health \& Nutrition ${ }^{2}$, and Paediatrics and Child health ${ }^{3}$, Obafemi Awolowo University Teaching Hospital and Obafemi Awolowo University, Ile-Ife, Nigeria

\begin{abstract}
Background: Little information is available about the aetiology and epidemiology of serious bacterial infections in Nigeria. This study determined bacterial isolates from blood and cerebrospinal fluid (CSF) of children presenting in the emergency room of a teaching hospital in Nigeria.

Method: From October 2005 to December 2006, children aged two to 60 months presenting with signs of acute systemic infections were recruited. Blood culture and CSF specimens were collected and processed using standard microbiological protocols. Data were analysed using SPSS version 11 software.

Results: Two hundred and two blood and 69 CSF samples were cultured. Fifty-five (27\%) of the blood cultures yielded Gram-negative bacilli and Gram-positive cocci in almost equal proportions. The most common isolates from the blood cultures were Staphylococcus aureus, 26 (12.9\%) and atypical coliforms, 13 (6.5\%). Others are Klebsiella spp, 3 (1.5\%); Klebsiella pneumonia, 2 (1.0\%); Escherichia coli, 3 (1.5\%); Enterobacter agglomerans, 2 (1.1\%); Proteus mirabilis, 2(1\%); Pseudomonas spp, 2 (1.0\%); Haemophilus influenza, 1 (1.0\%); and Coagulase-negative Staphylococcus, 1 (1.0\%). Fourteen out of $67(20.9 \%)$ of the CSF samples yielded bacterial isolates: Streptococcus pneumonia, 3 (4.5\%); Haemophilus influenza, 8 (11.9\%); Hemophilus spp, 1 (1.5\%); E. Coli, 1 (1.5\%); and atypical coliform, 1 (1.5\%). Gram-negative coliform isolates were predominantly resistant to penicillin based antibiotics and co-trimoxazole but sensitive to thirdgeneration cephalosporins and quinolones. A high percentage of $S$. aureus isolates were multi-drug resistant.

Conclusions: Bacterial infections contribute to the significant morbidity among children in our environment. S. aureus was more frequently isolated in sepsis while $H$. influenzae appears to play a major role in meningitis. Appropriate use of antibiotics is needed to manage affected children effectively. We also recommend improved vaccine coverage of children under the age of five years.
\end{abstract}

Keywords: bacterial agents, sepsis, meningitis, children, Nigeria

J Infect Dev Ctries 2009; 3(6):429-436.

Received 28 March 2009 - Accepted 4 June 2009

Copyright $\odot 2009$ Onipede et al. This is an open access article distributed under the Creative Commons Attribution License, which permits unrestricted use, distribution, and reproduction in any medium, provided the original work is properly cited.

\section{Introduction}

Invasive bacterial diseases are a major cause of childhood morbidity and mortality. It has been estimated that $30-50 \%$ of children born in a rural setting in Africa will probably die before the age of five years without any medical intervention [1]. The majority of these deaths are not investigated as most health facilities lack the resources for doing microbiologic studies [2]; furthermore, associated factors include delayed presentation to the hospital, poor health systems (low vaccine coverage) and infrastructure, and poorly motivated health staff [3].

Until now, community-based studies of death among children have suggested that the most important cause of death among children in Africa is malaria; however, the methodology of these studies has been questioned [2]. More recent community- based studies of the incidence of invasive bacterial disease in rural Gambia and Kenya [4-8] have all documented a significant contribution of invasive bacteria disease to childhood morbidity and mortality in developing countries. These studies showed that the minimum estimated incidence of communityacquired bacteremia $(\mathrm{CAB})$ and the case fatality rate in each of these countries were significantly higher than those recorded in many industrialized countries [9].

Etiologic causes of community-acquired bacteria infection are usually due to those organism associated with respiratory diseases in children, but enteric bacteria have also been noted to be as important [2,5]. In addition, a variety of opportunistic pathogens presents great challenges to the diagnostic laboratory in the developing country setting. Due to 
these challenges, treatment is usually based on clinical symptoms and knowledge of the epidemiologic pattern of local pathogens often leading to inappropriate treatment as well as increased morbidity and mortality [3,10]. Many of these deaths probably had underlying invasive bacterial diseases but were not investigated. With the worldwide increase in the incidence of bacteria resistant to several antimicrobial agents [11], periodic bacteriologic surveillance of invasive bacteria disease from normally sterile sites (e.g. blood cultures and CSF) where appropriate are important to confirm clinical diagnoses, conduct accurate infectious disease surveillance, and direct public health care policy [10]. This study reports the pattern of isolates from children with invasive bacterial disease from a pilot surveillance in a Nigerian teaching hospital.

\section{Materials and Methods}

\section{Study setting}

This was a laboratory-based and clinical prospective surveillance of invasive bacteria diseases (pneumonia, sepsis, and meningitis) in Obafemi Awolowo University Teaching Hospitals Complex, (OAUTHC) Ile-Ife from October 2005 to December 2006. The OAUTHC is a tertiary referral hospital in Southwestern Nigeria. It receives patients mainly from Osun-State where it is located and from the neighbouring states. All patients admitted for acute signs of systemic infections were reviewed using a standardized study protocol. The protocol collected socio-demographic characteristics, clinical symptoms, prior antibiotics use, physical signs, and the results of investigations. Ethical approval for the study was obtained from the OAUTHC Research and Ethical Committee and informed consent was obtained from all the parents or guardians.

\section{Study population}

The inclusion criterion was any child whose age was between 2-60 months presenting at the paediatric emergency with systemic infection based on any of the following features: fever $\left(\geq 38^{\circ} \mathrm{C}\right)$ or hypothermia $\left(\leq 36^{\circ} \mathrm{C}\right)$; cough; fast breathing; difficulty in breathing; or convulsion and with a clinical diagnosis of pneumonia, meningitis or sepsis. Neonates and any child without any of these features were excluded. Laboratory evaluation for blood culture and CSF in particular among other investigations were collected as part of usual routine investigations conducted in acutely ill children. CSF was obtained only if neurological signs were present and blood was collected from all respondents in a prospective cohort study of 383 admissions. All children whose parents declined participation were excluded.

\section{Laboratory methods}

Blood culture: We collected 1-5 mls of venous blood per set into Tryptone soya broth with sodium polyanathol sulfate (Oxoid) under aseptic conditions preferably before the start of antibiotic therapy. Samples were transported to the laboratory within 30 minutes of collection. The blood cultures were incubated at $37^{\circ} \mathrm{C}$ aerobically and subcultured on Columbia II agar base (Oxoid Ltd., Basingstoke, UK) with 5\% sheep blood, chocolate agar (in candle extinction) and MacConckey agar (Difco/BD Diagnostic Systems, Sparks, MI, USA). The isolates were identified by standard methods, including colony morphology, Gram stain, coagulase test and the use of MICROBACT12E for Gram negative bacilli. Blood cultures were examined after 24 and 48 hours and then every day for up to seven days.

Cerebrospinal fluid (CSF): The attending physician, with meticulous aseptic technique, collected CSF $(5-6 \mathrm{ml})$ in sterile specimen tubes preferably before commencement of antibiotics. CSF specimens were sent immediately to the laboratory for Gram stain, culture for bacteria on a supplemented chocolate agar plate (in a $5 \% \mathrm{CO}_{2}$ atmosphere), sheep blood agar plate and MacConkey agar incubated at $35-37^{\circ} \mathrm{C}$. Isolates were identified using standard bacteriologic and biochemical methods [12]. Antibiotic sensitivity patterns of bacterial isolates were determined by agar diffusion method using antibiotic discs [13].

\section{Results}

Of 1,949 children who were seen in the children's emergency during the period of the study, 383 presented with signs suggestive of acute bacterial infection. Two hundred and thirteen $(55.6 \%)$ satisfied the inclusion criteria and were enrolled into the study. The study group was comprised of 111 males and 102 females with an age range from two to 60 months (Median $11.9 \pm 6.42$ months). Sixty-three (29.6\%) children had a diagnosis of sepsis (21 female and 42 males); 47 (22.1\%) meningitis (25 female and 22 males), and 103 (48.3\%) pneumonia (56 females and 47 males). The majority of the children (185/213; $86.8 \%$ ) had a favorable outcome. There were 21 deaths (occurred mostly within two days of admission); one patient recovered with 
complication from meningitis; and six absconded (i.e. sought voluntary discharge to seek coliform organism except in cases of pneumonia. The distribution of isolates from blood culture was similar

Table 1. Patients' outcome and clinical diagnosis.

\begin{tabular}{ccccc}
\hline Outcome & $\begin{array}{c}\text { Meningitis } \\
\mathbf{N}(\boldsymbol{\%})\end{array}$ & $\begin{array}{c}\text { Pneumonia } \\
\mathbf{N}(\boldsymbol{\%})\end{array}$ & $\begin{array}{c}\text { Sepsis } \\
\mathbf{N}(\boldsymbol{\%})\end{array}$ & $\begin{array}{c}\text { Total } \\
\mathbf{N}(\boldsymbol{\%})\end{array}$ \\
\hline Well & $34(72.3)$ & $91(88.3)$ & $60(95.2)$ & $185(86.8)$ \\
Well + complicated & $1(2.1)$ & - & - & $1(0.5)$ \\
Absconded & $2(4.2)$ & $2(1.9)$ & $2(3.2)$ & $6(2.8)$ \\
Died & $10(21.3)$ & $10(9.7)$ & $1(1.6)$ & $21(9.9)$ \\
\hline Total & $47(100)$ & $103(100)$ & $63(100)$ & $213(100)$ \\
\hline
\end{tabular}

cheaper alternative care, mainly due to financial constraints). Etiological agents were similar in patients that died compared to those that survived where there was an isolate from the CSF or blood culture. However, among patients that died, 10 and 8 , respectively, had no growth from blood culture and CSF. The outcome with respect to clinical diagnosis is shown in Table 1. Furthermore, $105(49.3 \%)$ of the patients had received one form of antibiotics or the other based on the information from mothers/guardians, either purchased directly over the counter or prescribed from the local health centre before presenting at the hospital.

Blood cultures were performed for 202 patients (as the clinical condition dictates) and $69 \mathrm{CSF}$ samples collected (47 from children with diagnosis of meningitis and 22 from children with either diagnosis of sepsis or pneumonia but with a suspected meningitis picture) and examined for bacterial etiology. From the blood cultures, 55 (27.2\%) were positive for bacterial growth yielding Gram-negative bacilli (GNB); 28 and Gram positive cocci (GPC); 27 in almost equal proportion. Six (3\%) were of polymicrobial growth and were classified as contaminants and $141(69.8 \%)$ had no growth. The distribution of bacterial isolates from blood cultures is presented in Table 2. Staphylococcus aureus $(26 ; 12.8 \%)$ was the most common GPC organism while the predominant Gram negative organisms were unidentified Gram negative rods; coliforms $13(6.4 \%)$. Identifiable gram-negative organisms isolated include: Klebsiella spp, 3 (1.5\%); Klebsiella pneumonia, 2 (1.0\%); Escherichia coli, 3 (1.5\%); Enterobacter agglomerans, 2 (1.0\%); and other organisms as presented in Table 2. However, no S. pneumoniae was recovered from blood cultures. Table 3 shows the distribution of bacterial isolates by diagnosis. $S$. aureus and Klebsiella spp were commonly isolated across the spectrum of diagnosis of pneumonia, sepsis or meningitis and likewise for unidentified across all age groups (data not shown).

From direct smear microscopy, Gram-positive cocci (GPC) were identified in four (5.8\%) smears, while $11(15.9 \%)$ had Gram-negative bacilli (GNB) with pus cells. Fifty-four $(78.3 \%)$ were smearnegative on direct microscopy. However, during culture, two CSF specimens were contaminated and excluded from further analysis. Of the remaining 67 CSF specimens, $53(79.1 \%)$ yielded no growth on culture. Culture positive CSF specimens yielded $S$. pneumoniae $(3 / 67 ; 4.5 \%), \quad H$. influenzae (8/67; $11.9 \%$ ) while Haemophilus spp, E. coli and atypical coliform were each $1 / 67 ; 1.5 \%$.

Table 2. Microbial isolates from blood cultures (BC) of children studied.

\begin{tabular}{|l|l|l|}
\hline Blood isolates & Frequency n & \% \\
\hline Pseudomanas spp & 2 & $(1.0)$ \\
\hline Haemophilus influenzae & 1 & $(0.5)$ \\
\hline Escherichia coli & 3 & $(1.5)$ \\
\hline Enterobacter agglomerans & 2 & $(1.0)$ \\
\hline Klebsiella pneumoniae & 2 & $(1.0)$ \\
\hline Klebsiella spp & 3 & $(1.5)$ \\
\hline Proteus mirabilis & 2 & $(1.0)$ \\
\hline Coliform & 13 & $(6.4)$ \\
\hline Staphylococcus aureus & 26 & $(12.8)$ \\
\hline $\begin{array}{l}\text { Coagulase-negative } \\
\text { Staphylococcus }\end{array}$ & 1 & $(0.5)$ \\
\hline Contaminants & 6 & \\
\hline No growth & 141 & $(3.0)$ \\
\hline Total & $\mathbf{2 0 2}$ & $\mathbf{1 0 0}$ \\
\hline
\end{tabular}

The antibiotics sensitivity pattern of isolates is as presented in Tables $4 a$ and $b$. Gram negative bacilli isolates from blood culture were predominantly resistant to penicillin based antibiotics and cotrimoxazole but sensitive to third-generation 
Table 3. Blood culture organism with respect to diagnosis.

\begin{tabular}{|c|c|c|c|c|}
\hline \multirow[b]{2}{*}{ Organism } & \multirow[b]{2}{*}{ Meningitis } & \multicolumn{2}{|c|}{ Primary Diagnosis } & \multirow[t]{2}{*}{ Total } \\
\hline & & Pneumonia & Sepsis & \\
\hline $\begin{array}{l}\text { H. influenzae } \\
\text { E. coli }\end{array}$ & $\begin{array}{l}1(2.2) \\
-\end{array}$ & $\begin{array}{l}- \\
-\end{array}$ & $\begin{array}{l}- \\
3(4.9)\end{array}$ & $\begin{array}{l}1(0.5) \\
3(1.5)\end{array}$ \\
\hline $\begin{array}{l}\text { Proteus mirabilis } \\
\text { Enterobacter } \\
\text { agglomerans }\end{array}$ & $\overline{1}(2.2)$ & $-\overline{1}(1.0)$ & $\begin{array}{l}2(3.3) \\
-\end{array}$ & $\begin{array}{l}2(1.0) \\
2(1.0)\end{array}$ \\
\hline Klebsiella pпеитопiae & - & - & $2(3.3)$ & $2(1.0)$ \\
\hline $\begin{array}{l}\text { Klebsiella. spp } \\
\text { Pseudomonas spp }\end{array}$ & $1(2.2)$ & $\begin{array}{l}1(1.0) \\
1(1.0)\end{array}$ & $\begin{array}{l}1(1.6) \\
1(1.6)\end{array}$ & $\begin{array}{c}3(1.5) \\
2(1.0)\end{array}$ \\
\hline Staphylococcus aureus & $5(11.1)$ & $15(15.6)$ & $6(9.8)$ & $26(12.9)$ \\
\hline $\begin{array}{l}\text { Coagulase Negative } \\
\text { Staphylococcus }\end{array}$ & $1(2.2)$ & - & - & $1(0.5)$ \\
\hline Coliform & $3(6.7)$ & - & $10(16.4)$ & $13(6.4)$ \\
\hline No growth & $33(73.3)$ & $75(78.1)$ & $33(54.0)$ & $141(69.8)$ \\
\hline Total & $45(100.0)$ & $96(100.0)$ & $61(100.0)$ & $202(100)$ \\
\hline
\end{tabular}

cephalosporin and quinolone. From the isolates tested, Haemophilus influenzae was also resistant to erythromycin, while isolates of Enterobacter agglomerans were sensitive to co-trimoxazole. The Klebsiella pneumonie that was isolated shared the same antibiotic profile with Klebsiella spp as presented in Table 4a. A high percentage of $S$. aureus isolates from blood were multiply resistant across different classes of antibiotics but coagulase-negative Staphylococcus (CoNS) was resistant to cotrimoxazole, and erythromycin. From the CSF isolates tested (Table 4b), $H$. influenzae was generally resistant to co-trimoxazole, erythromycin, amoxicillin-clavulanic acid and gentamicin but more than sixty percent sensitive to ceftriazone and ciprofloxacin. S. pneumoniae was sensitive to erythromycin, amoxicillin-clavulanic acid, chloramphenicol and ceftriaxone but resistant to gentamicin and co-trimoxazole.

\section{Discussion}

Invasive bacterial diseases continue to exact a devastating impact on childhood morbidity and mortality in this environment considering that one out of 10 of children enrolled in the study died after admission despite medical intervention. However, this is less than the estimated $50 \%$ mortality rate that may occur in the rural African setting without medical intervention (WHO 1999). Although 87\% had a favorable outcome, the findings have established the magnitude of invasive bacterial disease in children in this environment, corroborating the observation of similar studies elsewhere [4-8]. In this study, most deaths occurred within the first two days of admission; this observation reflects the usually poor state of the patient at presentation and the delay in reporting to the hospital. This perhaps is a reflection of the poor health system, low vaccine coverage, poor infrastructure and lack of resources for doing microbiologic studies as reported by others $[2,3]$. Considering the late presentation and severity of some of the children's illness, $49 \%$ of mothers acknowledged that they have used one form of antibiotics or the other either prescribed at a district health facility or bought over the counter. This may have led to the use of an inappropriate drug or dose, thereby exacerbating the children's illness which may lead to acquired bacterial resistance to antibiotics. The socioeconomic and behavioral factors underpinning the misuse of antibiotics in developing countries have been reported by Okeke et al. [14]. Furthermore, premature antibiotic use, which is common in the developing countries impact negatively on the efforts of microbiology to isolate the clinically relevant organism and to perform antibiotics susceptibility testing [10]. In a study from Southern regions of Nigeria, referral and previous care in health facilities were significantly 
Table 4a. Antimicrobial sensitivity pattern of isolates from blood culture

\begin{tabular}{|c|c|c|c|c|c|c|c|c|c|c|c|c|}
\hline \multirow[b]{2}{*}{ Isolate } & \multicolumn{12}{|c|}{$\%$ of isolates $(\mathrm{n}) *$ susceptible to antimicrobial agents } \\
\hline & GEN & AMP & STX & TET & AUG & OXA & ERY & CHL & OFX & CFZ & CIP & AXO \\
\hline E. coli & $\begin{array}{l}\mathbf{1 0 0} \\
(3)\end{array}$ & $\begin{array}{l}50 \\
\text { (3) }\end{array}$ & - & - & $\begin{array}{l}100 \\
(2)\end{array}$ & - & - & - & $\begin{array}{l}\text { 100 } \\
\text { (1) }\end{array}$ & - & $\begin{array}{l}100 \\
(3)\end{array}$ & $\begin{array}{l}100 \\
(2)\end{array}$ \\
\hline P. mirabilis & $\begin{array}{l}100 \\
(2)\end{array}$ & $\begin{array}{l}50 \\
(2)\end{array}$ & $\begin{array}{l}50 \\
(2)\end{array}$ & $\begin{array}{l}\mathbf{5 0} \\
(2)\end{array}$ & - & - & - & & $\begin{array}{l}100 \\
(2)\end{array}$ & - & - & - \\
\hline Klebsiella spp & $\begin{array}{l}100 \\
(3)\end{array}$ & 0 (3) & $\begin{array}{c}0 \\
(1)\end{array}$ & & $\begin{array}{l}100 \\
(2)\end{array}$ & - & - & - & $\begin{array}{l}\text { 100 } \\
\text { (3) }\end{array}$ & - & $\begin{array}{l}\text { 100 } \\
(1)\end{array}$ & $\begin{array}{l}\mathbf{1 0 0} \\
(2)\end{array}$ \\
\hline $\begin{array}{l}\text { Pseudomonas } \\
\text { spp }\end{array}$ & O (2) & $\begin{array}{l}\mathbf{0} \\
(2)\end{array}$ & - & - & $\begin{array}{l}0 \\
(2)\end{array}$ & - & - & - & $\begin{array}{l}\text { 100 } \\
\text { (1) }\end{array}$ & $\begin{array}{l}\text { 100 } \\
(2)\end{array}$ & $\begin{array}{l}100 \\
(1)\end{array}$ & $\begin{array}{l}100 \\
(1)\end{array}$ \\
\hline S. aureus & $\begin{array}{l}62.5 \\
(8)\end{array}$ & $\begin{array}{l}40 \\
(20)\end{array}$ & - & $\begin{array}{l}25 \\
(16)\end{array}$ & $\begin{array}{l}71.4 \\
(21)\end{array}$ & $\begin{array}{l}50 \\
(22)\end{array}$ & $\begin{array}{l}61.9 \\
(21)\end{array}$ & $\begin{array}{l}70.6 \\
(17)\end{array}$ & $\begin{array}{l}\text { 100 } \\
\text { (4) }\end{array}$ & - & $\begin{array}{l}83.3 \\
(5)\end{array}$ & $\begin{array}{l}87.5 \\
(8)\end{array}$ \\
\hline Coliform & $\begin{array}{l}\text { 100 } \\
(5)\end{array}$ & - & $\begin{array}{l}16.7 \\
(6)\end{array}$ & $\begin{array}{l}60 \\
(5)\end{array}$ & $\begin{array}{l}37.5 \\
(8)\end{array}$ & - & - & $\begin{array}{l}100 \\
(1)\end{array}$ & $\begin{array}{l}100 \\
(6)\end{array}$ & - & $\begin{array}{l}100 \\
(5)\end{array}$ & $\begin{array}{l}83.3 \\
(6)\end{array}$ \\
\hline
\end{tabular}

Legend: *Figures in parenthesis show number of isolates tested. GEN $=$ Gentamicin

$\mathrm{AMP}=$ Ampicillin

TET $=$ Tetracyclin

OXA $=$ Oxacillin

STX= Trimethoprim/Sulfamethoxazole

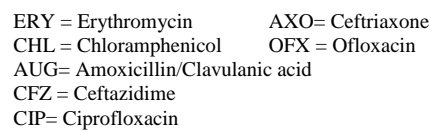

$\mathrm{CIP}=$ Ciprofloxacin

associated with delayed presentation, partial treatment, atypical signs, severity of illness and adverse outcome, which are all factors affecting neonates, while the cited studies included neonates and a large review of blood culture sets over several years from routine laboratory practice compared to

Table 4b. Antimicrobial sensitivity pattern of isolates from CSF culture.

\begin{tabular}{|l|l|l|l|l|l|l|l|l|l|l|l|l|}
\hline \multicolumn{10}{|c|}{ \% of isolates susceptible to antimicrobial agents } \\
\hline Isolate (n) & GEN & AMP & AUG & OXA & STX & ERY & CHL & OFX & TET & CIP & AXO \\
\hline S. pneumo (3) & 0 & 100 & 100 & 100 & 33.3 & 100 & 100 & 66.7 & - & - & 100 \\
\hline $\begin{array}{l}\text { H. influenzae } \\
\text { (8) }\end{array}$ & $\mathbf{0}$ & 40 & 50 & 0 & 0 & 20 & 80 & 66.7 & 33.3 & 66.7 & 66.7 \\
\hline $\begin{array}{l}\text { Haemophilus. } \\
\text { spp (1) }\end{array}$ & - & 100 & 100 & - & - & - & 100 & 100 & - & 100 & 100 \\
\hline E. coli (1) & 100 & 100 & - & - & - & - & - & 100 & - & - & - \\
\hline Coliform (1) & 100 & - & - & - & - & - & - & 100 & - & - & 100 \\
\hline
\end{tabular}

Legend:

GEN $=$ Gentamicin

$\mathrm{AMP}=$ Ampicillin

$\mathrm{AUG}=$ Augmentin

OXA $=$ Oxacillin

STX= Trimethoprim/Sulfamethoxazole

CIP=Ciprofloxacin

laboratory culture yield of the clinically relevant organism [15].

In our study, $27 \%$ of blood cultures yielded bacterial growth, which is low when compared with higher rates of $30-55 \%$ reported from children with provisional diagnosis of sepsis in other parts of the country [16-19]. This difference may be explained by the differences in the population studied, whether children of all age groups were included, or whether the study included neonates. Our study was restricted to children younger than five years of age, excluding research settings. In agreement with previous studies, all the microorganisms isolated in this study have been reported as causes of bacterial infection in young children $[15,16,20]$ : However, in contrast to other studies reporting a preponderance of Grampositive organisms [16-20], our findings show that Gram-negative bacilli (GNB) and Gram-positive cocci (GPC) were recovered in almost equal proportion in our setting. S. aureus was the most common Gram-positive organism isolated, which confirms the increasing role of this pathogen in invasive bacterial infection as documented by other centres in Nigeria [16-18]. Our findings indicate that 
children diagnosed provisionally with pneumonia were more likely to have $S$. aureus isolate from blood culture. This may be due to the inability of these children to localize infection which may invariably become generalized, as has been suggested by other investigators [21]. The limited number of $S$. pneumoniae and $H$. influenzae isolated may be due to the prior use of antibiotics purchased over the counter before presenting to the hospital since these are less hardy organisms. Other Gram-negative organisms isolated are consistent with what has been reported in other centres in childhood sepsis [16-21].

Even though the isolation of an organism from a blood culture is considered significant, the exclusion of bacteremia is also important when a negative blood culture result is returned by the laboratory, provided that adequate blood volume was cultured [22]. In our study about $70 \%$ of blood culture was negative for bacteria growth and this enabled the cessation of antibiotic treatment, and reduced the length and cost of hospital stay with the potential of preventing the development of antimicrobial resistance from avoidable antibiotic prescription [2325 ].

In children suspected with meningitis, our study achieved a culture positive rate of $20.8 \%$ for CSF. This observation agrees with studies from other centres in the country, where rates ranging from 12$39 \%$ have been reported [15, 26-29]. Improving the culture positive rate of CSF in the laboratory has always been very challenging in developing country settings, with several diagnostic difficulties usually contributing factors $[10,14,15,28]$. We endeavored to deal with some of these challenges with the introduction of Trans-Isolate medium during the course of the study, which however, did not yield an appreciable growth of pathogens from CSF samples. This may be due to the antibiotics patients might have received before specimen collection. Improvement in institutional capacity and technical proficiency are needed to ameliorate the yield from blood and CSF cultures in developing countries in patients with clinical evidence of invasive bacterial disease as has been advocated by others $[3,10]$.

The pattern of bacteria isolates reported in this study from CSF is also consistent with what was reported from other centres in the country except that meningococcal meningitis is not common in the southern part of the country where our hospital is located [15,26-28]. Furthermore, the southern parts of Nigeria record only sporadic cases of meningitis compared to the northern parts where epidemic cases of meningitis have occurred in the past [29]. Our study indicates that $S$. pneumoniae is less frequently isolated compared to Haemophilus from children with meningitis in this setting. The age distribution of isolates is consistent with established patterns of pathogens responsible for pyogenic meningitis in children [26-28].

With respect to the in vitro sensitivity pattern of bacteria isolates in this study, our observation is consistent with earlier reports from the same study centre [16-21].

The main limitation of this study is that it is not a population-based study. Also, basing the data of this study on a single blood culture is also an important limitation. This is due to several challenges associated with following guidelines in a developing country setting. Apart from the well-known issue of limited resources, there are important cultural barriers or misperceptions to overcome; for instance, mothers are reluctant to have their children bled more than once or are suspicious of the true intent of investigators. Furthermore, there was no attempt made to assess the level of prior antibiotic use in our study population by undertaking urine or serum antimicrobial activity testing, which may have impact on the recovery rate of organisms.

In conclusion, invasive bacterial infections are a common cause of morbidity and mortality in children under the age of five years in our setting. The study also confirms the importance of bacteria isolates such as $S$. aureus and Gram-negative coliform organisms as leading causes of sepsis. The presence of multidrug resistant isolates causing invasive disease is of great concern and calls for the introduction a national policy, which makes it difficult to procure antibiotics across the counter without a prescription. Epidemiological surveillance studies on a countrywide basis are required to provide useful information to guide practice and policies on rational use of anti-microbial agents and vaccine coverage for children under the age of five years.

\section{Acknowledgements}

This was a pilot study designed to investigate invasive pneumococcal disease. The authors thank all the contributors to the pilot study, as well as the hospital and university staff for their support. We also acknowledge Prof R. A. Adegbola, MRC-The Gambia, for his supervisory support at the conceptual stage, for his technical advice, and for accepting to read through the manuscript. 
"This publication was supported by a subcontract from The Johns Hopkins University with funds provided by The Boards of the Global Alliance for Vaccines and Immunizations and the Vaccine Fund (GAVI) ("Agency"). Its contents are solely the responsibility of the authors and do not necessarily represent the official views of the Agency."

\section{References}

1. Clinical signs of serious infections in young infants in developing countries: a WHO collaborative study (1999) Pediatr Infect Dis J18 (10 suppl): S1-69.

2. Mulholland EK, Adegbola RA (2005) Bacterial infections: a major cause of death among children in Africa. $\mathrm{N}$ Engl $\mathrm{J}$ Med 352: 75-77.

3. Bates I and Maitland K (2006) Are Laboratory Services Coming of Age in Sub-Saharan Africa? Clinical Infectious Diseases 42: 383-4.

4. Berkley JA, Lowe BS, Mwangi I, et al. (2005) Bacteremia among children admitted to a rural hospital in Kenya. N Engl J Med 352: 39-47.

5. O’Dempsey TJ, Mcardle TF, Lloyd-Evans N, et al. (1994) Importance of enteric bacteria as a cause of pneumonia, meningitis and septicemia among children in a rural community in The Gambia, West Africa. Pediatr Infect Dis J 13: $122-128$.

6. Campbell JD, Kotloff KL, Sow SO, et al. (2004) Invasive pneumococcal infections among hospitalized children in Bamako, Mali. Pediatr Infect Dis J 23: 642-649.

7. Bahwere P, Levy J, Hennart P, et al. (2001) Communityacquired bacteremia among hospitalized children in rural central Africa. Int J Infect Dis 5: 180 -188.

8. Walsh AL, Phiri AJ, Graham SM, Molyneux EM, Molyneux ME (2000) Bacteremia in febrile Malawian children: clinical and microbiologic features. Pediatr Infect Dis J 19: 312-318.

9. Enwere G, Biney E, Cheung Y, Zama SM Okoko B, Oluwalana O, Vaughan A, Greenwood B, Adegbola R, Cutts FT (2006) Epidemiologic and Clinical Characteristics of Community-Acquired Invasive Bacterial Infections in Children Aged 2-29 Months in The Gambia Pediatr Infect Dis J 25: 700-705.

10. Petti CA, Polage CR, Quinn TC, Ronald AR, Sande MA (2006) Laboratory Medicine in Africa: A Barrier to Effective Health Care. Clinical Infectious Diseases 42: $377-$ 82.

11. Pinner RW, Rebmann CA, Schuchat A, Hughes JM (2003) Disease surveillance and the academic, clinical, and public health communities. Emerg Infect Dis 9: 781-7.

12. Finegold SM, Markin WJ, Scott EJ (1978) Bailey \& Scott's Diagnostic Microbiology 5th edition. St. Louis: The CV Mosby Company.

13. NCCLS (1997) Performance standards for antimicrobial disk susceptibilitytests. Approved standard M2-A6, 7th ed. National Committee for ClinicalLaboratory Standards, Wayne, Pa.

14. Okeke IN, Lamikanra A, and Edelman R (1999) Socioeconomic and Behavioral Factors Leading to Acquired Bacterial Resistance to Antibiotics in Developing Countries. Emerg Infect Dis 5: 18-27.
15. Akpede GO, Omoigberale AI, Dawodu SO, Olomu SC, Shatima DR, Apeleokha M (2005) Referral and previous care of children with meningitis in Nigeria: implications for the presentation and outcome of meningitis in developing countries. J Neurol Sci 228: 41-8.

16. Meremikwu MM, Nwachukwu CE, Asuquo AE, Okebe JU, Utsalo SJ (2005) Bacterial isolates from blood cultures of children with suspected septicaemia in Calabar, Nigeria. BMC Infectious Diseases 5: 110.

17. Antia-Obong OE, Utsalo SJ, Udo JJ, Udo KT (1992) Neonatal septicaemia in Calabar, Nigeria. Cent Afr J Med 38:1 61-5.

18. Mokuolu AO, Jiya N, Adesiyun OO (2002) Neonatal septicaemia in Ilorin: bacterial pathogens and antibiotic sensitivity pattern. Afr J Med Med Sci 31: 127-30.

19. Ako-Nai AK, Adejuyigbe EA, Ajayi FM, Onipede AO (1999) The bacteriology of neonatal septicaemia in Ile-Ife, Nigeria. J Trop Pediatr 45: 146-51.

20. Adejuyigbe EA, Adeodu OO, Ako-Nai KA, Taiwo O, Owa JA (2001) Septicaemia in high risk neonates at a teaching hospital in Ile-Ife, Nigeria. East Afr Med J 78: 540-3.

21. Adejuyigbe EA, Ako-Nai AK, Adisa B (2004) Bacterial isolates in the sick young infant in Ile-Ife, Nigeria. J Trop Pediatr50: 323-7.

22. Connell TG, Rele M, Cowle D, Buttery JP, Curtis N (2007) How Reliable Is a Negative Blood Culture Result? Volume of Blood Submitted for Culture in Routine Practice in a Children's Hospital PEDIATRICS 119: 5 www.pediatrics.org/cgi/doi/10.1542/ peds.2006-0440.

23. Isaacman DJ, Karasic RB, Reynolds EA, Kost SI (1996) Effect of number of blood cultures and volume of blood on detection of bacteremia in children. J Pediatr 128:190-195.

24. Byl B, Clevenbergh P, Jacobs F, et al. (1999) Impact of infectious diseases specialists and microbiological data on the appropriateness of antimicrobial therapy for bacteremia. Clin Infect Dis 29: 60-66.

25. Szymczak EG, Barr JT, Durbin WA, Goldmann DA (1979) Evaluation of blood culture procedures in a pediatric hospital. J Clin Microbiol 9: 88-92.

26. Emele FE (2000) Etiologic spectrum and pattern of antimicrobial drug susceptibility in bacterial meningitis in Sokoto, Nigeria. Acta Paediatr 89: 942-6.

27. Johnson AW, Mokuolu OA, Onile BA (1992) Chloramphenicol-resistant Haemophilus influenzae meningitis in young urban Nigerian children. Acta Paediatr 81: 941-3.

28. Imananagha KK, Peters EJ, Philip-Ephraim EE, Ekott JU, Imananagha LN, Ekure EN, Esin RA (1998) Acute bacterial meningitis in a developing country: diagnosis related mortality among paediatric patients. Cent Afr J Med. 44: 115.

29. Mohammed I, Nasidi A, Alkali AS, Garbati MA, Ajayi-Obe EK, Audu KA, Usman A, Abdullahi S (2000) A severe epidemic of meningococcal meningitis in Nigeria, 1996. Trans R Soc Trop Med Hyg. 94: 265-70. 


\section{Corresponding Author}

Dr. Anthony O. Onipede

Department of Medical Microbiology \& Parasitology

Obafemi Awolowo University
Ile-Ife, Nigeria

aonipede@ oauife.edu.ng

Conflict of interest: No conflict of interest is declared. 